\title{
A apropriação de habilidades de leitura e escrita na alfabetização: estudo exploratório de dados de uma avaliação externa
}

\author{
Gladys Rocha* \\ Raquel Fontes-Martins**
}

\section{Resumo}

Este trabalho analisa o desenvolvimento de habilidades de escrita nos primeiros anos do Ensino Fundamental, referenciando-se na avaliação em larga escala da alfabetização, de caráter longitudinal, denominada Programa de Avaliação da Educação Básica do Estado do Espírito Santo - Paebes Alfa. Os dados de escrita são analisados também em sua interlocução com a leitura. Assim, além de serem discutidos tipos de itens de escrita utilizados nessa avaliação externa à escola, realiza-se uma análise que oferece contribuição para a apreensão de diferenças entre habilidades de leitura e de escrita, ainda frequentemente entendidas como "faces de uma mesma moeda", ou seja, como aprendizagens que ocorrem simultânea e indistintamente. Como a análise aqui feita indica, na consolidação do processo de alfabetização, habilidades de decodificação tendem a ocorrer antes de habilidades de codificação.

Palavras-chave: Avaliação externa. Escrita. Ensino fundamental. Paebes Alfa.

\section{Introdução}

Este trabalho ${ }^{1}$ analisa o desenvolvimento de habilidades de escrita nos primeiros anos do Ensino Fundamental, tendo como referência a avaliação em larga escala da alfabetização, realizada no Estado do Espírito Santo desde 2008, o Programa de Avaliação da Educação Básica do Estado do Espírito Santo - Paebes Alfa.

\footnotetext{
* Pós Doutorado em Políticas Públicas em Educação, PUC-Rio; Professora do Departamento de Métodos e Técnicas de Ensino da Faculdade de Educação. Universidade Federal de Minas Gerais - FaE/UFMG. Email: gladysrocha1@gmail.com.

** Doutora em Linguística, Universidade Federal de Minas Gerais; Professora do Departamento de Ciências Humanas. Universidade Federal de Lavras - UFLA. Email: raquelfontesmartins@gmail.com

1 Este artigo constitui um recorte de uma pesquisa mais ampla: "Meta-avaliação da alfabetização: uma investigação do papel e potencialidade de itens e escalas de escrita", financiada pelo Instituto Nacional de Estudos e Pesquisas Educacionais Anísio Teixeira - INEP, do Ministério da Educação - MEC/ Brasil, que possibilitou a constituição de um corpus longitudinal de itens de escrita infantil de cerca de 300.000 alunos.
} 
A opção por essa avaliação se relaciona ao fato de que esse Programa é o único no país a avaliar o ensino fundamental a partir do ingresso dos alunos nessa modalidade de ensino e de modo longitudinal até o terceiro ano de escolaridade, período no qual se espera que as crianças estejam alfabetizadas. Esse desenho de avaliação se efetiva por meio de suas duas edições no $1^{\circ}$ ano do ensino fundamental (uma no início - Avaliação de Entrada e outra no final - Avaliação de Saída) e uma Avaliação de Saída para os alunos do $2^{\circ}$ e do $3^{\circ}$ ano, o que permite que um mesmo aluno possa ser avaliado por até quatro vezes. Também, faz-se necessário ressaltar que, apesar da potencialidade dos dados do Paebes Alfa para estudos longitudinais, neste trabalho, a análise foi transversal, considerando os dados de cerca de 380.000 alunos de diferentes anos de escolaridade e diferentes edições (Entrada e Saída de cada ano de aplicação - de 2010 a 2011 e Entrada - 2012). Também, embora o Paebes Alfa avalie alfabetização, leitura, escrita e matemática, focalizamos apenas a alfabetização em leitura e escrita, "atribuindo ao termo letramento seu sentido literal referindo-nos exclusivamente à leitura e à escrita". (SOARES, 1999, p. 67).

Tem-se assim que o Paebes Alfa, para além de compor um quadro nacional ainda recente de avaliar os alunos cada vez mais precocemente, visando à obtenção de informações sobre o sistema que permitam intervenções também mais precoces, avança nesse movimento ao avaliar longitudinalmente, respaldado pelo desenho da pesquisa Geração Escolar 2005 - Geres ${ }^{2}$. Avança ainda, em relação à própria Pesquisa Geres ao permitir a apreensão do que a escola efetivamente agrega à aprendizagem dos estudantes, aferindo os conhecimentos com os quais o aluno ingressa no primeiro ano do ensino fundamental.

No que se refere ao escopo específico deste estudo, destaca-se o ineditismo do Paebes Alfa ao incluir a escrita na avaliação. Nessa direção, cabe também destacar a Avaliação Brasileira do Final do Ciclo de Alfabetização - Prova $\mathrm{ABC}^{3}$, que avalia uma amostra de alunos de $2^{\circ} \mathrm{e} 3^{\circ}$ ano, e foi a primeira avaliação de abrangência nacional no âmbito do Ensino Fundamental a incluir a escrita. Contudo, tal avaliação, face aos seus objetivos, apresenta uma metodologia

2 A Pesquisa Geres representa no Brasil o primeiro estudo longitudinal a investigar desempenhos de alunos dos primeiros anos de escolaridade do ensino fundamental em Língua Portuguesa - Leitura e em Matemática, e fatores sociofamiliares que podem incidir sobre o desempenho escolar. Participaram da pesquisa cerca de 20.000 alunos de escolas públicas, privadas e do estrato especial (federais) das cidades de Belo Horizonte, Campinas, Campo Grande, Rio de Janeiro e Salvador. Face ao seu caráter inovador e a aspectos de caráter técnico e financeiro, essa pesquisa focalizou, em Língua Portuguesa, apenas a constituição de competências leitoras.

3 Avaliação implementada em 2011 a partir de parceria entre o "Todos pela Educação", Fundação Cesgranrio, Instituto Nacional de Estudos e Pesquisas Educacionais Anísio Teixeira - INEP e Instituto Paulo Montenegro/IBOPE. 
diferente de aplicação, pressupondo um aluno capaz de ler, sem mediação, os enunciados dos testes e, talvez por isso, mais adequada ao público do $3^{\circ}$ ano. Em 2013, a experiência da Prova ABC é incorporada e ampliada pelo INEP, que passa a ter na Avaliação Nacional da Alfabetização - ANA, o único teste voltado ao Ensino Fundamental a incorporar a escrita. Assim como a Prova $\mathrm{ABC}$, a ANA pressupõe a leitura autônoma dos itens e volta-se para o $3^{\circ}$ ano.

Apesar desses avanços, antes de tratar do recorte deste estudo, cabe evidenciar, também, que subjaz a ele uma concepção de avaliação como instrumento que permite apreender importantes habilidades e competências. Contudo, estas são restritas em relação à sala de aula e previamente delimitadas em função dos limites de o que e como se pode medir em um instrumento que pretende aferir o domínio de habilidades e competências, não do ponto de vista do ensino, mas do direito à aprendizagem e do compromisso político e social com ela.

No caso específico da avaliação da alfabetização e do letramento, faz-se necessária a clareza de que estamos considerando a dimensão individual do letramento, sem perder de vista sua indissociabilidade da dimensão social. Isso significa que, embora se conceba o letramento como prática social, o foco da avaliação é o domínio, pelo indivíduo, de habilidades e competências de leitura e escrita. Entretanto, o fato de estabelecer o recorte na dimensão individual do letramento, não torna a tarefa simples (SOARES, 1999, p. 63-64). Envolve a delimitação de habilidades e competências fundamentais na aprendizagem, passíveis de serem aferidas nos limites de um conjunto de testes externos à escola, ainda que estes sejam aplicados longitudinalmente. No caso do Paebes Alfa engloba habilidades de leitura e escrita nos três primeiros anos do ensino fundamental,

Além da delimitação de habilidades e competências, avaliar a alfabetização e o letramento envolve, também, outra dificuldade que, segundo Soares (1999, p. 67-70), atinge o cerne da questão: o fato de o letramento envolver dois processos fundamentalmente diferentes, porém, complementares: ler e escrever.

É exatamente nessa dimensão que se situa este estudo exploratório ${ }^{4}$. Pretendese, a partir de dados de escrita do Paebes Alfa em sua interlocução com a leitura, discutir as seguintes questões:

4 Este texto representa uma primeira aproximação com os dados em estudo. A construção de medidas de valor agregado e o estudo de trajetórias de apropriação da escrita a partir de corpus longitudinal permitirão a delimitação de estudos mais aprofundados e com diferentes recortes, do ponto de vista da apropriação da escrita. 
- O que os itens de escrita, aqui traduzidos a partir de escalas de proficiência informam sobre o desenvolvimento de habilidades na alfabetização?

- Que aproximações, distanciamentos ou singularidades são identificados nas escalas de leitura e escrita?

Orienta essas questões a compreensão de que a escrita é uma dimensão essencial do letramento e, em decorrência, da alfabetização e do ensino de língua portuguesa. Considerando que a avaliação se relaciona ao ensino, na medida em que focaliza habilidades e/ou competências que o aluno deveria apreender, é fundamental que a escrita seja objeto de avaliação tanto interna quanto externa, para diagnóstico de habilidades que os alunos demonstram dominar, estar em apropriação ou ainda não conhecer.

Entretanto, as definições de letramento que orientam as avaliações, como mostra Soares (1999, p. 68),

frequentemente tomam a leitura e a escrita como uma mesma e única habilidade, desconsiderando as peculiaridades de cada uma e as dessemelhanças entre elas (uma pessoa pode ser capaz de ler, mas não ser capaz de escrever; ou alguém pode ler fluentemente, mas escrever muito mal).

Convergindo com essa percepção, os dados oriundos de avaliações externas à escola no campo da alfabetização, não raro, têm nas habilidades de leitura os indicadores de alfabetização para leitura e escrita, como se houvesse simultaneidade na sua apropriação, como se, ao domínio de determinadas habilidades de leitura, correspondesse, também, o da escrita. No caso das avaliações externas, a ênfase na aferição da leitura em detrimento da escrita se deve, para além do aumento de custos e da complexidade da logística, a uma dificuldade específica da própria avaliação no que concerne ao tratamento metodológico dos itens de escrita, tanto na sua proposição e correção, quanto na construção de escalas 5 .

5 O Programa de Avaliação da Alfabetização do Estado de Minas Gerais - Proalfa, em sua edição amostral em 2005 e nas edições censitárias de 2006 e 2007 avaliou leitura e escrita, mas em função de dificuldades técnicas, metodológicas e à época também de logística, em 2008, passou a avaliar apenas leitura. Situação similar se observou em relação à Provinha Brasil, que só apresentou itens de escrita em sua primeira edição, em 2008. Apesar dessas dificuldades e de as metodologias de aplicação e correção de itens de escrita, bem como a produção de escalas de proficiência de escrita, estarem em construção, o Paebes Alfa assumiu o desafio de fazê-lo. 


\section{Reflexões sobre a avaliação da escrita}

Como mencionado, avaliar a escrita do aluno é importante porque a escrita é uma dimensão essencial do letramento e, por isso, fundamental na alfabetização e no ensino de língua portuguesa (SOARES, 1999; COSTA VAL et al., 2009; MARCUSCHI, 2008).

Em uma avaliação externa, o que avaliar é expresso em uma matriz de referência em forma de habilidades e competências de escrita que, se espera, o aluno domine. No caso de habilidades de escrita na alfabetização, o que e o para que avaliar estão dimensionados pelo domínio individual do letramento, mediatizados, dentro do possível, pelos usos que se faz da palavra escrita na vida social, e aos conhecimentos necessários ao aluno para que se torne um usuário competente da língua em sua modalidade escrita (SOARES, 1999; ANTUNES, 2003). No caso do Paebes Alfa, a matriz expressa os saberes que se espera que o aluno domine até o terceiro ano de escolarização do ensino fundamental em duas dimensões: [1] o domínio da "tecnologia da escrita", e [2] sua utilização. Parte-se, assim, do pressuposto de que o acesso à palavra escrita envolve, para além do letramento, a apropriação de uma "técnica". Como explicita Soares (2003, p. 1-2):

O que poderíamos chamar de acesso ao mundo da escrita - num sentido amplo - é o processo de um indivíduo entrar nesse mundo, e isso se faz basicamente por duas vias: uma, através do aprendizado de uma "técnica". Chamo a escrita de técnica, pois aprender a ler e a escrever envolve relacionar sons com letras, fonemas com grafemas, para codificar ou para decodificar. Envolve, também, aprender a segurar um lápis, aprender que se escreve de cima para baixo e da esquerda para a direita; enfim, envolve uma série de aspectos que chamo de técnicos. A outra via, ou porta de entrada, consiste em desenvolver as práticas de uso dessa técnica. Não adianta aprender uma técnica e não saber usá-la.

A dimensão técnica da escrita supõe, por exemplo, o domínio do sistema de meios gráficos da língua, o qual inclui a apreensão dos grafemas (implementados pelas letras), o posicionamento e a combinação de grafemas no contexto de uma palavra, bem como o uso de sinais que modificam o valor sonoro das letras como o til, o cedilha, o acento agudo, o circunflexo. A apropriação e o uso 
competente da palavra escrita demandam, assim, a apropriação das ferramentas que permitem codificar; o domínio da técnica (SOARES, 1999; 2003).

Para além do domínio da técnica, as habilidades de escrita são, assim como as de leitura, utilizadas em materiais escritos distintos - os gêneros textuais. Esses são, por sua vez, relacionados e conformados pelas necessidades, objetivos e contextos nos quais são produzidos.

O domínio competente da escrita demanda, assim,

desde a habilidade de transcrever a fala, via ditado, até habilidades cognitivas e metacognitivas; inclui a habilidade motora (caligrafia), a ortografia, o uso adequado da pontuação, a habilidade de selecionar informações sobre determinado assunto, e de caracterizar o público como leitor, a habilidade de estabelecer metas para a escrita e decidir qual a melhor forma de desenvolvê-la, a habilidade de organizar ideias em um texto escrito, estabelecer relações entre elas, expressá-las adequadamente. Além disso, as habilidades de escrita, tal como as de leitura, devem ser aplicadas diferenciadamente à produção de uma variedade de materiais escritos: da simples assinatura do nome à elaboração de uma lista de compras até a redação de um ensaio ou de uma tese de doutorado. (SOARES, 1999, p. 70).

Detendo-nos nas especificidades dos itens de escrita, foco deste trabalho, podese dizer que a dimensão técnica é expressa nos testes por questões relacionadas ao uso da página; à escrita de palavras e frases, com itens de escrita de palavras em número maior que os demais. Nesses casos não há, nos testes, a preocupação com uma interlocução mais próxima com práticas reais de leitura. Isso porque se trata de habilidades específicas, muito típicas do contexto escolar, voltadas intencionalmente para o ensino, cuja contextualização depende, fundamentalmente, da mediação docente. Há, entretanto, na definição das palavras propostas, a preocupação com a frequência de uso da palavra tendo em vista o público-alvo da avaliação, contexto e faixa etária do aluno, além de aspectos próprios da constituição interna da palavra, tratados mais adiante.

Na delimitação das frases, a fim de contextualizar minimamente a atividade e constituir sentido ao enunciado proposto para a escrita, o encadeamento dos 
termos priorizou a apresentação de uma ação ou um acontecimento simples, em princípio, facilmente apreensível pelo aluno. Considerou-se, também, a frequência dos termos que a compunham - optando-se por palavras mais frequentes na língua -, a estrutura fonética e/ou fonêmica desses termos (número de sílabas, tonicidade, tipos de sílabas etc.), além da sua sintaxe (ordem direta sujeito, verbo, complemento/ adjunto adverbial, preferencialmente).

$\mathrm{Na}$ dimensão do uso, figura, fundamentalmente, a produção de textos de diferentes gêneros considerados adequados à faixa etária e ao período de escolarização. Entende-se o texto como uma "proposta de compreensão" que o sujeito-autor faz ao seu interlocutor e, nesse processo, desenvolve ações com e sobre a linguagem (GERALDI, 1991). As ações com a linguagem dizem respeito às reflexões que o sujeito faz em torno do processo de constituição do texto, do seu conteúdo e significado. As ações sobre a linguagem estão relacionadas aos processos de reflexão sobre a língua, inerentes ao processo de escritura (GERALDI, 1991, p. 160). Essas ações integram, além da construção de um todo coerente e articulado adequadamente em um gênero, habilidades específicas como utilização de meios gráficos para distribuição da escrita nas linhas e parágrafos; indicação de título; uso adequado de letra maiúscula e de sinais de pontuação, entre outras habilidades.

Observa-se, assim, uma proposta de avaliação que, em sua acepção, visa integrar as dimensões técnica e social da escrita. Entretanto, apesar desse movimento, é preciso considerar que o próprio ato de avaliar a escrita e de fazê-lo numa avaliação externa à escola delineia as condições de produção do texto escrito, o que restringe as possibilidades de proposição do dizer e suas razões, de delimitação das estratégias do dizer e, sobretudo, de indicação de um leitor-modelo, que acaba configurado quase que exclusivamente pela situação de avaliação.

Assim, avaliar a escrita no contexto da alfabetização e letramento pressupõe, por um lado, a apreensão do por quê, para quê e o quê avaliar em suas duas dimensões. Pressupõe, por outro lado, a apreensão dos limites e possibilidades dos modos de apresentação e apreensão do objeto. Demanda, também, a clareza de que no âmbito da avaliação externa, minimizar as diferenças entre as práticas de produção textual propostas e as vivenciadas fora da escola consitui tarefa ainda mais complexa do que já o é no âmbito do ensino. No Paebes Alfa, 
procurou-se contextualizar, dentro do possível, as propostas de produção, mas, como mencionado, embora se contemplem diferentes gêneros, a delimitação de um leitor-modelo para além do próprio avaliador é muito difícil.

Essas variáveis são, no entanto, inerentes à própria avaliação do letramento. Como explicita Soares (1999, p. 115), "o letramento não pode ser avaliado e medido de forma absoluta, apesar de a delimitação de índices de letramento ser imprescindível para a formulação de políticas, o planejamento, a implementação e o controle de programas". Tem-se, como decorrência dessa complexidade, a possibilidade de apreender apenas parte das habilidades e competências inerentes à palavra escrita. No que tange ao texto, por exemplo, focalizam-se aspectos relativos ao gênero, considerando suas características como objeto linguístico produzido para determinado fim. Esse movimento impõe, obviamente, algumas limitações já que não é possível captar processos de aprendizagem ou reconhecer, tal como se pode fazer no contexto da sala de aula, aspectos relacionados ao processo criativo do aluno, ao planejamento, ou ao modo como o leitor interviria no próprio texto em outra situação de interlocução.

É importante, portanto, circunscrever a avaliação da palavra escrita quer em sua dimensão técnica, quer em sua dimensão social, como instrumento que possibilita, a partir da apreensão de habilidades e competências, uma aproximação do nível de desenvolvimento real do aluno em relação à tarefa proposta. Em decorrência dessa especificidade, uma chave de correção, por mais abrangente que pretenda ser, acaba por privilegiar determinadas competências e habilidades em detrimento de outras. Acredita-se, no entanto, que as capacidades e competências avaliadas, embora não sejam suficientemente abrangentes, englobam competências fundamentais na apropriação de determinado conhecimento, como a de escrever palavras de uso frequente na língua, com diferentes estruturas silábicas, ou a de redigir um conto. Assim, se por um lado, as chaves de correção não contemplam a amplitude de habilidades e competências próprias do processo de aprendizagem, permitem apreender habilidades fundamentais, cuja didatização faz-se necessária.

Considera-se aqui que o papel da avaliação é o de aproximação do nível de desenvolvimento real do aluno ou de um conjunto de alunos em relação a determinadas habilidades e competências, em dado momento. A avaliação é 
entendida, portanto, como instrumento que possibilita uma aproximação, uma apreensão mais clara de aspectos relacionados à apropriação e ao desenvolvimento de habilidades de escrita pela criança, mas não os define, ou os circunscreve. Pode-se utilizar aqui a metáfora da fotografia, já que a avaliação permite um delineamento do olhar, a percepção de uma parte de um percurso ou paisagem que, ao focalizar determinado ponto acaba, inevitavelmente, por negligenciar outro, o que não destitui dela seu potencial, o delimita apenas.

Delineado o quadro geral, no qual se orienta a avaliação da escrita neste trabalho, a próxima seção apresenta o detalhamento dos diferentes tipos de itens de escrita aplicados no Paebes Alfa. Esse detalhamento permitirá uma visão mais clara dos modos de apresentação dos itens, de suas especificidades e finalidades, bem como de habilidades a eles subjacentes.

\section{Tipos de itens de escrita adotados no Paebes/ Alfa}

Avaliar a escrita de crianças em processo de alfabetização é uma atividade complexa, tendo em vista a dinamicidade da aprendizagem da escrita nesse período. Considerando desde os níveis pré-silábico e silábico, passando pela escrita alfabética ou alfabético-ortográfica de palavras e frases, até a produção de textos escritos, há um grande espectro de aprendizagem que deve ser previsto na avaliação da escrita (FERREIRO, TEBEROSKY, 1985; ANTUNES, 2003; DOLZ, GAGNON, DECÂNDIO, 2010). É por esse motivo que, no Paebes Alfa, se avalia desde a escrita de palavras até a produção de textos escritos, procurando considerar aspectos relacionados à aquisição do sistema de escrita até a ampliação da capacidade redacional do aluno.

Os itens de escrita das avaliações são analisados de forma politômica. O diferencial do item politômico é que ele apresenta uma "graduação hierarquizada" de respostas, para a análise dos registros feitos pelos sujeitos avaliados. Isso quer dizer que são consideradas desde a melhor resposta até a resposta menos plausível, passando, também, por respostas intermediárias: nem totalmente corretas, nem totalmente inadequadas. Os itens politômicos têm esse nome porque, diferentemente dos itens de múltipla escolha - geralmente analisados de forma dicotômica, ou seja, em termos do certo e do errado -, as diferentes respostas dos alunos são analisadas para se conhecer o padrão de desempenho de cada aluno em relação à habilidade de escrita avaliada. No caso do Paebes 
Alfa, os itens de escrita consideram cinco possibilidades de respostas (ou seja, uma resposta mais adequada, três intermediárias e uma menos adequada).

Diferentemente dos itens de leitura dos testes, que são dicotômicos e, por isso mesmo, passíveis de correção através de leitura ótica de cartões de respostas, ou de sua digitação, avaliar a escrita tem sido um desafio, pois implica um grande esforço em sua correção ${ }^{6}$. Faz-se necessária a produção de uma chave (ou tábua) de correção que contemple, ainda que com limitações, parte significativa das possíveis escritas produzidas pelos alfabetizandos. Realiza-se um treinamento com a equipe de corretores para explicar a proposta e tentar minimizar diferenças de interpretação das tábuas e, durante o processo de correção, devese estar, através dos supervisores de equipes, sempre atento à análise da escrita das crianças, cabendo até modificações na chave, quando necessário.

Os instrumentos de avaliação da alfabetização, leitura e escrita do Paebes-Alfa, produzidos para o Paebes Alfa, têm apresentado três tipos básicos de itens de escrita, descritos a seguir: a escrita de palavras, a de frases e a produção de textos escritos.

\subsection{Escrita de palavras}

Os itens que avaliam a escrita de palavras utilizam recursos distintos: [1] a estratégia de apresentar apenas figuras referentes às palavras que os alfabetizandos deverão escrever sem que essas palavras ocorram no enunciado do item, que focaliza o estímulo visual e propõe uma situação na qual o aluno não pode retomar, durante a escrita, o desenho, cujo nome precisa ser escrito, e [2] itens em que a palavra a ser registrada pelo aluno é ditada para ele pelo aplicador do teste, com foco no estímulo auditivo e no qual a interferência da oralidade é marcada pelas pronúncias do aplicador e do aluno. A opção pela utilização desses dois tipos de itens devese ao fato de os estudos indicarem que esses diferentes estímulos subjacentes aos modos de proposição da escrita de palavras interferem de modo distinto na resposta produzida pelo aluno e relaciona-se a um conjunto de variáveis que vão desde o grau de familiaridade com a palavra, sua variação dialetal em dada comunidade até o reconhecimento da imagem, entre outros aspectos. Entretanto, como não se tem dados empíricos que nos permitam uma apreensão mais clara das singularidades e/ ou interferências do uso de uma e outra estratégia, optou-se por propor, em todos os

6 Aspectos inerentes ao trabalho com itens de escrita na avaliação externa, como o "efeito da escolha dos gêneros textuais" em diferenças de desempenho em anos de escolaridade distintos, e a aspectos teórico-metodológicos da correção, embora também constituam objeto de pesquisadas autoras, não são abordados aqui por extrapolarem os propósitos deste estudo. 
testes, itens com os dois tipos de estímulo. A expectativa é a de que, num momento em que a compreensão da avaliação da escrita e sua implementação estiverem um pouco mais consolidadas, sejam desenvolvidos estudos com esse foco.

$\mathrm{Na}$ produção dos itens de escrita de palavras, buscou-se contemplar as diferentes estruturas silábicas que devem ser testadas. Assim, são propostas escritas de palavras que contenham a sílaba CV (consoante/ vogal) como nas palavras GATO e PETECA; a sílaba CVC (consoante/ vogal/ consoante) como em BARCO e PASTA; a sílaba CCV (consoante/ consoante/ vogal) como em PREGO e PLACA; a sílaba VC (vogal/ consoante) como em ARCA e ESTRELA; a sílaba V (vogal) como em ABACAXI e UVA; e sílabas que contenham ditongos em qualquer posição, como em BALÃO e OURO.

Além da estrutura silábica, outra preocupação na formulação de itens de escrita de palavras é contemplar palavras com diferentes números de sílabas (monossílabas, dissílabas, trissílabas, polissílabas) e diferentes tipos de acento (monossílabo tônico, oxítono, paroxítono e proparoxítono). Também, são priorizados substantivos de sentido concreto, os quais favorecem a compreensão das figuras pelos alunos e a identificação da palavra a ser escrita. Ainda, palavras mais frequentes na língua e mais familiares aos alunos da faixa etária avaliada são focalizadas.

Ainda quanto à escrita de palavras, é preciso destacar que, no caderno de teste do aluno, não há enunciados. Estes só aparecem no caderno do professor. $\mathrm{O}$ aluno só tem acesso às figuras que se referem às palavras avaliadas. Essa estratégia de não apresentar as palavras escritas visa a impedir tanto a cópia dessas palavras como a facilitar a identificação das palavras que o aluno deverá escrever. Vale destacar que, no caso da escrita de palavras com apoio de imagens, a seleção adequada de figuras, em todos os tipos de itens, é muito importante. São priorizadas imagens mais claras, com contorno bem definido e que focalizem apenas as palavras a serem avaliadas.

\subsection{Escrita de frases}

Similarmente ao que se observa em relação às palavras, a escrita de frases tem sido testada de duas maneiras diferentes. Na primeira delas, apresenta-se uma cena que permita ao aluno apreender um personagem realizando determinada ação (geralmente reproduzida de livros de literatura infantil) e solicita-se que o 
aluno escreva uma frase, contando o que está acontecendo na cena apresentada. Mais uma vez, toma-se todo o cuidado para que, na elaboração dos itens de escrita a partir de uma cena, a seleção de imagens seja adequada. É de suma importância que elas sugiram algum acontecimento passível de ser contado em uma frase pelo aluno. Nesse tipo de item, não há um controle sobre todas as palavras que o aluno vai escrever, já que ele tem certa liberdade para selecionar as palavras com que vai elaborar sua frase, dentro dos limites do que é sugestionado pela cena, pois os principais elementos composicionais da frase já estão dados.

Diferentemente, na segunda proposta de escrita de frases, os alunos devem escrever uma frase ditada pelo aplicador do teste. Na elaboração das palavras que compõem os itens de escrita de frases ditadas, são controlados o tamanho e a complexidade sintática da frase, ou seja, se ela está formulada na ordem direta (sujeito - verbo - complemento) ou não. Também, como a frase é constituída de palavras, são observados os mesmos aspectos da elaboração dos itens de escrita de palavras, explicitados anteriormente: as estruturas silábica e acentual, o número de sílabas, a frequência e a familiaridade das palavras.

Avaliar os dois tipos de itens de escrita de frase (frase escrita a partir de uma cena e frase ditada) é importante porque tanto a experiência de sala de aula quanto estudos acadêmicos demonstram que um aluno que escreve uma determinada palavra corretamente quando ela está sozinha, pode escrevê-la de modo errado quando ela se encontra no contexto de uma frase. A principal explicação para isso é que, isoladamente, as palavras são pronunciadas de uma forma; em uma frase, podem ser pronunciadas de outra, o que interfere na escrita (ROCHA et al., 2010).

\subsection{Produção de textos escritos}

O Paebes Alfa promove a avaliação da produção escrita, apresentando os seguintes tipos de itens:

- Produção de lista a partir de uma cena: é apresentada uma cena com objetos, a partir da qual o aluno deve produzir um texto no gênero lista (de brinquedos, de objetos escolares, de utensílios de cozinha, etc.). Nesse item, é avaliado se o aluno escreveu uma lista de três a cinco elementos que aparecem na cena proposta, dispondo as palavras no modo habitual do gênero, ou seja, em coluna (uma palavra embaixo da outra) na página. 
- Reconto a partir de cenas de uma história: são apresentadas ao aluno cenas de uma história (como uma tirinha, uma história em quadrinhos curta ou uma história em cenas) que deve ser recontada por ele. Nesse item, o gênero reconto de história em cenas é focalizado. Espera-se que o aluno produza um reconto plausível em relação às cenas da história e que apresente: (1) personagens praticando ações em uma sequência temporal; (2) articuladores (como os marcadores temporais "então" e "depois"); e (3) recursos coesivos (como pronomes, descrições definidas e elipses) que favoreçam a progressão ou continuidade temática para o texto não ficar repetitivo.

- Bilhete: é proposta ao aluno a escrita de um texto no gênero bilhete, com uma determinada finalidade e tema, e com um destinatário definido (colegas, professora, pais, etc.). É avaliado se o aluno escreveu o seu texto de acordo com o tema proposto, construindo a estrutura básica do bilhete: vocativo (expressão usada para dirigir-se ao destinatário, no início do bilhete); corpo/ conteúdo do bilhete, assinatura.

- Convite: na escrita do gênero convite (que guarda semelhanças com o bilhete), avalia-se se o aluno escreveu um texto de acordo com o propósito solicitado no enunciado (convidar alguém para uma festa, uma reunião, uma inauguração, uma exposição...), construindo a estrutura completa do convite: vocativo (expressão usada para dirigir-se a alguém, no início do convite), corpo/conteúdo do convite que deve conter o motivo do convite, a data, a hora e o local da realização do evento e o nome de quem está convidando.

- Cartão: na escrita do gênero cartão (que também apresenta semelhanças com o bilhete e o convite), é avaliado se o aluno escreveu um texto de acordo com o propósito solicitado no enunciado (cumprimentar alguém pelo seu aniversário, pelo "Dia do Professor"; desejar "Feliz Ano Novo", "Feliz Páscoa"...), construindo a estrutura completa do cartão: vocativo (expressão usada para dirigir-se a alguém, no início do cartão), corpo/ conteúdo do cartão, assinatura e data.

- Conto/ história (real ou fictício): nesse item, avalia-se se o aluno escreveu um conto/história coerente com a proposta feita (relato de episódio de medo, susto, surpresa, alegria...). É avaliado se sua história apresenta três elementos principais: (1) personagem(ns) praticando ações em uma sequência temporal; (2) articuladores (como os marcadores temporais "um dia", "uma vez", "então", "depois"...); e (3) recursos coesivos (como a retomada de 
termos através de pronomes, descrições definidas e elipses) que favorecem a progressão ou continuidade temática, para o texto não ficar repetitivo.

Na elaboração das propostas dos itens de produção de texto especificados a partir do terceiro tópico, pela própria situação de avaliação censitária, não se considera recomendável apresentar condições de produção muito detalhadas, especialmente para alunos dos primeiros anos de escolaridade, sob pena de o enunciado se tornar muito complexo e dificultar a compreensão da proposta. Contudo, destaca-se que, em situação de sala de aula, é altamente recomendável que as condições de produção sejam bem especificadas na proposta de produção de textos.

Vale ressaltar que, na avaliação dos itens de produção de textos escritos, consideram-se duas dimensões: a discursiva e a linguística, que envolvem ações com e sobre a linguagem (GERALDI, 1991). Na dimensão discursiva, avalia-se se o aluno entendeu a proposta feita, no que se refere ao gênero proposto (por exemplo, lista, bilhete, convite, cartão e conto), aos destinatários (pais, professores, colegas) e aos temas e propósitos (fazer compras, avisar que está doente, convidar para uma festa, cumprimentar pelo aniversário, relatar um episódio de susto, etc.).

Na dimensão linguística, são observados os seguintes aspectos: a ortografia, o uso de letras maiúsculas (especialmente em início de frase e em nomes próprios), pontuação (em especial o ponto em final de frase), acentuação gráfica e alguns casos de concordância verbal e nominal.

Essa forma de avaliação permite indiciar se a criança domina as duas dimensões, apenas uma delas ou se não domina nenhuma. Assim, em relação à escrita de textos, saber que dimensão(ões) os alunos dominam orienta o tipo de investimento a fazer: se é mais em uma ou em outra dimensão, ou nas duas igualmente.

Os dados disponibilizados pela avaliação censitária do Paebes Alfa oferecem contribuição para a construção de diagnósticos, possibilitando apreender melhor não somente diferenças entre dimensões da produção de textos escritos, mas entre os processos de apropriação de habilidades de leitura e de escrita, ainda frequentemente entendidos como "faces de uma mesma moeda", ou seja, como aprendizagens que ocorrem simultânea e indistintamente. Seria como se à aprendizagem da leitura correspondesse de per si a aprendizagem da escrita. A seguir, essa questão será tratada com 
uma análise de proficiências do Paebes Alfa, a qual considera a interação da leitura e da escrita no processo de alfabetização.

\section{Análise de proficiências no Paebes/ Alfa: interlocução dos processos de aprendizagem da escrita e da leitura}

Esta seção analisa os pontos da escala de proficiência identificados no Paebes Alfa que permitem dizer, em termos amplos, que o aluno está alfabetizado, para avaliar a interlocução dos processos de aprendizagem da escrita e da leitura.

A partir do desempenho demonstrado pelos alunos nas avaliações diagnósticas de 2009 a 2011, foram identificados dezessete níveis de proficiência (em uma escala de 0 a 1000) em Alfabetização/Língua Portuguesa, que apontam diferentes momentos na apropriação da palavra escrita. A proficiência de um aluno ou grupo de alunos representa, em um continuum de valores, um conjunto de habilidades que indiciam padrões de desempenho, que permitem traduzir medidas de proficiência em diagnósticos qualitativos. A partir da interpretação pedagógica, os dados foram organizados em quatro padrões de desempenho: Abaixo do Básico, Básico, Proficiente e Avançado. Em cada um desses padrões, é demonstrado, por ano de escolaridade, o conjunto de habilidades apresentado pelos alunos de modo autônomo, sem ajuda de colega(s) ou adulto mais experientes.

O Quadro a seguir apresenta dois padrões de desempenho que, no Paebes Alfa, permitem identificar um aluno ou grupo de alunos como alfabetizado.

\section{Quadro 1 - Padrões de Desempenho em Leitura e Escrita}

\begin{tabular}{|l|l|}
\hline Leitura & Escrita \\
\hline Proficiência a partir de 600 & Proficiência entre 850 e 900 \\
\hline - Informação explícita em textos curtos. & $\begin{array}{l}\text { - Escrita de frases curtas, com diferentes } \\
\text { estruturas silábicas, incluindo dígrafos, } \\
\text { ditongo e algumas irregularidades orto- } \\
\text { gráficas - em palavras mais frequentes na } \\
\text { língua e mais familiares ao universo infantil } \\
\text { - Identificação de suportes e gêneros textu sem uso de inicial maiúscula e/ou } \\
\text { ais mais familiares. } \\
\text { de pontuação adequada, com poucos erros } \\
\text { ortográficos. }\end{array}$ \\
- Inferência (inicial). & \multicolumn{2}{|l}{} \\
\hline
\end{tabular}

Fonte: Paebes Alfa (2012). 
Um aspecto que chama a atenção na síntese das habilidades demonstradas pelos examinandos é a diferença entre o conjunto de habilidades de leitura e de escrita. Observa-se que as habilidades de leitura são bem mais avançadas que as de escrita. No que se refere à competência leitora em constituição, o aluno já começa a lidar com textos mais amplos que a frase e inicia a capacidade de produção de inferência em texto mesmo que curto. Na escrita, no entanto, as habilidades demonstradas se situam ainda no nível da frase.

Tem-se, assim, que se se definissem pontos para identificar, numa avaliação externa à escola, a alfabetização no que tange à decodificação e à codificação, tais pontos seriam distintos. Em outras palavras, haveria "alfabetização em leitura ou decodificação" e "alfabetização em escrita ou codificação". Note-se que a decodificação figura no nível 600 da escala enquanto a codificação, bem mais embrionária, apenas a partir do nível 850 .

Esse achado sobre o aprendizado da leitura e da escrita relaciona-se ao que é apontado por alguns autores de que a aprendizagem da escrita seria mais complexa do que a da leitura no processo de alfabetização. Por exemplo, ScliarCabral (2003b, p. 123) afirma:

Em primeiro lugar deveremos partir do pressuposto de que escrever é mais complexo do que ler (...).

Partamos do primeiro momento em que o redator, movido por intenções pragmáticas quaisquer, resolva-se a escrever, selecionando esquemas mentais e registros linguísticos adequados a seus propósitos: há uma fase de planejamento que precede a linearização linguística, com inserção de itens lexicais nas casas de constituintes e respectivos comandos manuais, dependendo do suporte empregado para escrever. Apesar de estar se monitorando pari passu, o bom redator não encerra o seu trabalho de revisão.

Já em Cagliari (2008, p. 155) depreende-se que a escrita seria mais complexa do que a leitura na alfabetização ${ }^{7}$, quando o autor afirma que "para ler, são necessários alguns conhecimentos e, para escrever, além dos relacionados à

7 É importante ressaltar que essa diferença de complexidade na aprendizagem da leitura e da escrita é observada em um momento específico na alfabetização: quando o aluno se mostra alfabetizado, mesmo que com limitações no domínio de habilidades de leitura e de escrita. Em outros momentos de aprendizagem da língua, essa diferença pode não ser significativa, com leitura e escrita tendo um grau semelhante de complexidade. 
leitura, são necessários conhecimentos complementares". De fato, como afirma Cagliari, a escrita exige, além das habilidades de leitura, outras habilidades que lhe são peculiares tanto em um nível linguístico (uso adequado da página, grafia de letras, segmentação de palavras, domínio da ortografia, etc.) quanto em um nível discursivo (seleção de gênero textual adequado aos propósitos comunicativos, domínio de aspectos composicionais e de estilo de linguagem do gênero a ser produzido, revisão do texto escrito, etc.). Também, a afirmação de Cagliari aponta para uma precedência da leitura sobre a escrita, com o desenvolvimento de habilidades de leitura sendo como um "pré-requisito" para a aprendizagem da escrita.

Kato (2009, p. 122-123) nos faz refletir sobre essa diferença entre leitura e escrita quando afirma que

É preciso levar em conta pesquisas como a de Bryant e Bradley ${ }^{8}$, cujos resultados mostram que a criança, na fase de alfabetização, não usa necessariamente a mesma estratégia para escrever e para ler. Constatou-se que ela usa a estratégia fonológica (escrever como fala) apenas para escrever, mas não para ler. A estratégia, nessa atividade, é muito mais pautada em estratégias visuais inferenciais. Os autores mostram, por exemplo, que as crianças são capazes de ler palavras como bycicle e picture, embora não sejam capazes de escrevê-las, o que mostra que a leitura e a escritura apoiam-se, nessa fase, em estratégias diferentes.

Os resultados dessa pesquisa nos levam a supor que uma criança pode escrever leiti, usando a estratégia fonológica, mas não terá nenhum problema em ler a palavra grafada leite.

Esse comentário de Kato contribui para o entendimento da diferença observada no Quadro 1 para os padrões de desempenho em leitura e escrita, ou seja, para a compreensão sobre a diferença entre "alfabetização em leitura ou decodificação" e "alfabetização em escrita ou codificação".

Continuemos a discussão, agora tomando como referência a distribuição dos 147.938 alunos dos três primeiros anos do ensino fundamental avaliados em relação à leitura e à escrita, respectivamente, na análise das Tabelas 1 e 2.

8 BRYANT, P.; BRADLEY, L. Psychological strategies and the development of Reading and writing. In: Martlew, M. (Org.). The psycology of written language. Chichester, John Wiley and Sons, 1983. 
Tabela 1 - Proficiência em Leitura

\begin{tabular}{|c|c|c|c|c|c|c|}
\hline \multicolumn{7}{|c|}{ Proficiência em leitura } \\
\hline Série & Rede & \begin{tabular}{|c|} 
Abaixo do \\
Básico (até 400) \\
\end{tabular} & $\begin{array}{c}\text { Básico (400 a } \\
500)\end{array}$ & $\begin{array}{c}\text { Proficiente } \\
\text { (500 a 600) }\end{array}$ & $\begin{array}{c}\text { Avançado } \\
\text { (acima de 600) }\end{array}$ & Total \\
\hline \multirow{4}{*}{19 Ano } & Estadual & $5,6 \%$ & $15,7 \%$ & $24,1 \%$ & $54,5 \%$ & $100,0 \%$ \\
\hline & \begin{tabular}{|l|} 
Municipal \\
\end{tabular} & $10,9 \%$ & $24,9 \%$ & $28,8 \%$ & $35,4 \%$ & $100,0 \%$ \\
\hline & Particular & $0,9 \%$ & $9,3 \%$ & $29,1 \%$ & $60,7 \%$ & $100,0 \%$ \\
\hline & Total & $9,6 \%$ & $22,7 \%$ & $27,9 \%$ & $39,9 \%$ & $100,0 \%$ \\
\hline Série & Rede & \begin{tabular}{|c|} 
Abaixo do \\
Básico (até 500 )
\end{tabular} & $\begin{array}{c}\text { Básico (500 a } \\
600)\end{array}$ & $\begin{array}{c}\text { Proficiente } \\
(600 \text { a } 700)\end{array}$ & $\begin{array}{c}\text { Avançado } \\
\text { (acima de } 700 \text { ) }\end{array}$ & Total \\
\hline \multirow{4}{*}{ 20 Ano } & Estadual & $7,6 \%$ & $18,0 \%$ & $30,0 \%$ & $44,4 \%$ & $100,0 \%$ \\
\hline & Municipal & $11,8 \%$ & $24,7 \%$ & $33,2 \%$ & $30,4 \%$ & $100,0 \%$ \\
\hline & Particular & $2,5 \%$ & $9,3 \%$ & $34,8 \%$ & $53,4 \%$ & $100,0 \%$ \\
\hline & Total & $10,6 \%$ & $22,9 \%$ & $32,5 \%$ & $34,0 \%$ & $100,0 \%$ \\
\hline Série & Rede & \begin{tabular}{|c|} 
Abaixo do \\
Básico (até 600)
\end{tabular} & $\begin{array}{c}\text { Básico (600 a } \\
650)\end{array}$ & $\begin{array}{l}\text { Proficiente } \\
\text { (650 a } 750 \text { ) }\end{array}$ & $\begin{array}{c}\text { Avançado } \\
\text { (acima de } 750 \text { ) }\end{array}$ & Total \\
\hline \multirow{4}{*}{ 3Ano } & Estadual & $15,4 \%$ & $12,1 \%$ & $39,3 \%$ & $33,1 \%$ & $100,0 \%$ \\
\hline & Municipal & $23,2 \%$ & $15,9 \%$ & $37,9 \%$ & $23,0 \%$ & $100,0 \%$ \\
\hline & \begin{tabular}{|l|} 
Particular \\
\end{tabular} & $4,3 \%$ & $6,3 \%$ & $31,9 \%$ & $57,5 \%$ & $100,0 \%$ \\
\hline & Total & $21,7 \%$ & $15,1 \%$ & $37,9 \%$ & $25,3 \%$ & $100,0 \%$ \\
\hline
\end{tabular}

Fonte: Paebes Alfa (2012). 


\section{Tabela 2 - Proficiência em Escrita}

\section{Proficiência em escrita}

\begin{tabular}{c|c|r|r|r|r|r|}
\hline \multirow{2}{*}{ Série } & Rede & $\begin{array}{c}\text { Abaixo do } \\
\text { Básico (até 400) }\end{array}$ & $\begin{array}{c}\text { Básico (400 a } \\
500)\end{array}$ & $\begin{array}{c}\text { Proficiente } \\
(500 \mathrm{a} 600)\end{array}$ & $\begin{array}{c}\text { Avançado } \\
\text { (acima de 600) }\end{array}$ & Total \\
\hline \multirow{3}{*}{10 Ano } & Estadual & $8,7 \%$ & $19,2 \%$ & $30,7 \%$ & $41,4 \%$ & $100,0 \%$ \\
\cline { 2 - 7 } & Municipal & $12,1 \%$ & $22,9 \%$ & $28,6 \%$ & $36,3 \%$ & $100,0 \%$ \\
\cline { 2 - 7 } & Particular & $1,1 \%$ & $6,5 \%$ & $18,1 \%$ & $74,3 \%$ & $100,0 \%$ \\
\cline { 2 - 7 } & Total & $11,2 \%$ & $21,7 \%$ & $28,8 \%$ & $38,3 \%$ & $100,0 \%$ \\
\hline
\end{tabular}

\begin{tabular}{c|c|r|r|r|r|r|}
\hline \multirow{2}{*}{ Série } & Rede & $\begin{array}{c}\text { Abaixo do } \\
\text { Básico (até } 500)\end{array}$ & $\begin{array}{c}\text { Básico }(500 \text { a } \\
600)\end{array}$ & $\begin{array}{c}\text { Proficiente } \\
(600 \mathrm{a} 700)\end{array}$ & $\begin{array}{c}\text { Avançado } \\
(\text { acima de } 700)\end{array}$ & Total \\
\hline \multirow{3}{*}{ 2ㅇ Ano } & $12,2 \%$ & $18,5 \%$ & $37,2 \%$ & $32,1 \%$ & $100,0 \%$ \\
\cline { 2 - 7 } & Estadual & $14,7 \%$ & $19,8 \%$ & $36,3 \%$ & $29,1 \%$ & $100,0 \%$ \\
\cline { 2 - 7 } & Municipal & $1,4 \%$ & $4,7 \%$ & $34,9 \%$ & $59,0 \%$ & $100,0 \%$ \\
\cline { 2 - 7 } & Particular & $13,9 \%$ & $19,2 \%$ & $36,5 \%$ & $30,4 \%$ & $100,0 \%$ \\
\hline
\end{tabular}

\begin{tabular}{c|c|r|r|r|r|r|}
\hline \multirow{2}{*}{ Série } & Rede & $\begin{array}{c}\text { Abaixo do } \\
\text { Básico (até 600) }\end{array}$ & $\begin{array}{c}\text { Básico (600 a } \\
650)\end{array}$ & $\begin{array}{c}\text { Proficiente } \\
(650 \text { a 750) }\end{array}$ & $\begin{array}{c}\text { Avançado } \\
\text { (acima de 750) }\end{array}$ & Total \\
\hline \multirow{3}{*}{ 32 Ano Ano } & Estadual & $22,8 \%$ & $16,7 \%$ & $38,7 \%$ & $21,8 \%$ & $100,0 \%$ \\
\cline { 2 - 7 } & Municipal & $25,7 \%$ & $16,1 \%$ & $38,2 \%$ & $20,0 \%$ & $100,0 \%$ \\
\cline { 2 - 7 } & Particular & $2,7 \%$ & $8,1 \%$ & $38,1 \%$ & $51,1 \%$ & $100,0 \%$ \\
\cline { 2 - 7 } & Total & $24,7 \%$ & $15,9 \%$ & $38,2 \%$ & $21,1 \%$ & $100,0 \%$ \\
\hline
\end{tabular}

Fonte: Paebes Alfa (2012).

Uma análise comparativa das Tabelas 1 e 2 permite perceber que, de modo geral, em praticamente todos os anos de escolaridade e redes, há percentuais maiores de alunos nos padrões Proficiente e Avançado em leitura do que em escrita. Complementarmente, nota-se que há menores percentuais de alunos nos padrões Abaixo do Básico e Básico em leitura. Esse dado indica que os alunos demonstram melhor desempenho na leitura do que na escrita.

Embora seja necessário considerar o fato de a escala de escrita do Paebes Alfa estar ainda em constituição, seu caráter inovador em avaliações externas, e as limitações inerentes ao que uma avaliação dessa natureza pode informar, as evidências apontam diferenças significativas na apropriação e desenvolvimento de habilidades de leitura e de escrita, com essa última se consolidando mais tardiamente. Essas evidências convergem com a literatura da área (inclusive com trabalhos aqui citados) que, embora aponte para uma relação de interdependência entre esses objetos conceituais, aponta também para a não simultaneidade desses processos. Em outras palavras, embora ler e escrever sejam processos correlacionados, não são simultâneos (ORLANDI, 2000; SCLIAR-CABRAL, 2003a, 2003b). 
Os dados demonstram que o desenvolvimento de habilidades de leitura se consolida antes e de modo bem mais expressivo que o da escrita, já que o movimento entre a decodificação, atribuição de sentido às palavras, às frases e a outros textos de extensão e complexidade um pouco maiores, bem como as capacidades de relacionar informações de um texto para produção de inferências já se fazem presentes antes de habilidades de produção textual.

A escrita, como mencionado, fica restrita à frase, o que pode ser em parte explicado porque, na escrita, o aprendiz precisa lidar com elementos que na leitura já estão disponibilizados ao leitor (CAGLIARI, 2008). Embora a codificação seja entendida como um processo inverso à decodificação, ambas demandam a capacidade de percepção dos fonemas e sua conversão em grafemas e conhecimento dos nomes das letras, entre outras habilidades. Entretanto, a produção escrita pressupõe o domínio de habilidades específicas como a delimitação de espaços em branco entre as palavras, planejamento e definição do que e do como dizer, articulação das ideias em orações em um todo coerente, expresso na interlocução num determinado gênero, no uso de elementos coesivos e vocabulário adequado, pontuação, correção ortográfica, etc. Tais aspectos não são exigidos como produção no ato da leitura.

Outra variável que chama a atenção - talvez relacionada à falsa crença de simultaneidade na aprendizagem do ler e do escrever - é a apropriação das habilidades de decodificação e codificação de palavras, apresentada no Quadro 2.

\section{Quadro 2 - Nível 6 de Proficiência - escalas Leitura e Escrita}

\begin{tabular}{|l|l|l|}
\hline \multirow{4}{*}{ Nível 6} & $\begin{array}{l}\text { - Identificação, ainda em estágio } \\
\text { inicial, de sílaba CV de palavras } \\
\text { dissílabas e trissílabas, paroxítonas, } \\
\text { no início da palavra. }\end{array}$ & $\begin{array}{l}\text { - Cópia de uma frase, sem seguir } \\
\text { uma das regras de uso da página } \\
\text { no que diz respeito às margens e/ } \\
\text { ou à sequência da escrita (mudança } \\
\text { de linha). }\end{array}$ \\
& $\begin{array}{l}\text { - Leitura silenciosa de palavras dis- } \\
\text { sílabas, trissílabas, paroxítonas, com } \\
\text { estruturas silábicas diversas (sílaba } \\
\text { CV, CVC, VC, ditongo). }\end{array}$ & $\begin{array}{l}\text { - Início de escrita silábica ou silábi- } \\
\text { co-alfabética de palavras dissílabas, } \\
\text { trissílabas, paroxítonas, com sílabas } \\
\text { CV, CVC, CVV, especialmente (com } \\
\text { apoio de imagem). }\end{array}$ \\
\hline
\end{tabular}

Fonte: Paebes Alfa (2012). 
Como se observa, os processos de apropriação de habilidades de decodificação e codificação no contexto de palavras são mais próximos, embora guardem especificidades. Na codificação, o processo é inicial, com o começo de uma escrita silábica ou silábico-alfabética de palavras dissílabas, trissílabas, paroxítonas, com sílabas CV, CVC, CVV. Na leitura, os alunos leem palavras dissílabas, trissílabas, paroxítonas, com estruturas silábicas diversas (sílaba CV, CVC, VC, ditongo). Esse dado, embora, mais uma vez, aponte especificidades na apropriação da leitura e da escrita, indiciam que, nesse momento da alfabetização, a proximidade na apropriação de habilidades de codificação e decodificação é significativa, o que remete para a crença do ler e escrever como processos simultâneos não apenas do ponto de vista do ensino, mas também da aprendizagem.

\section{Considerações Finais}

Após refletir sobre algumas questões relacionadas à avaliação da escrita e de discutir tipos de itens de escrita, este trabalho apresentou um estudo exploratório sobre a interlocução da escrita e da leitura, tendo como referência dados da avaliação da alfabetização externa à escola, Paebes Alfa. Como visto, a análise indica que, apesar de serem processos relacionados, as aprendizagens da leitura e da escrita parecem não ocorrer ao mesmo tempo na fase de consolidação da alfabetização. Habilidades de decodificação tendem a ser aprendidas antes de habilidades de codificação, o que indica uma maior complexidade da escrita em relação à leitura nesse período de aprendizagem da língua.

Estabelecidos os limites da avaliação da escrita, há de se considerar a possibilidade de a esse quadro estarem subjacentes práticas de transposição didática cujo enfoque no desenvolvimento de habilidades de produção textual é menor do que no desenvolvimento de habilidades leitoras, talvez como decorrência da expectativa de uma alfabetização inicial mais consolidada para posterior investimento em habilidades mais "refinadas" de escrita. Podese considerar também a hipótese de que a escrita, embora bastante presente em turmas de alfabetização, ainda é muito atrelada a métodos que focalizam apenas a fonetização da escrita que fica mais circunscrita a atividades de cópia e transcrição, do que a atividades de produção textual propriamente.

De toda forma, os dados apresentados neste trabalho, apesar de sua grande representatividade pelo fato de derivarem da avaliação de cerca de 380.000 
alunos em até quatro aplicações do Paebes Alfa por aluno, no período 20102012, devem ser tomados como indiciários ainda. Será necessário empreender novos estudos, a fim de verificar a diferença aqui encontrada em relação à anterioridade da aprendizagem da leitura sobre a escrita na consolidação da alfabetização, o que aponta para uma maior complexidade da escrita nesse processo. Relatos na literatura (KATO, 2009; CAGLIARI, 2008; SCLIARCABRAL, 2003a, 2003b) corroboram esse achado. Contudo, estudos futuros e de caráter longitudinal permitirão analisar se essa diferença é significativa desde o início do processo de alfabetização e mesmo se ela continua sendo relevante após esse período.

\section{Referências}

ANTUNES, I. Aula de Português: encontro e interação. São Paulo: Parábola, 2003.

CAGLIARI, L. C. Alfabetizando sem o Bá-bé-bi-bó-bu. São Paulo: Scipione, 2008.

COSTA VAL, M. G. et al. Avaliação do texto escolar: Professor-leitor/ AlunoAutor. Belo Horizonte: Autêntica, 2009.

DOLZ, J.; GAGNON, R.; DECÂNDIO, F. Produção escrita e dificuldades de aprendizagem. São Paulo: Mercado de Letras, 2010.

FERREIRO, E.; TEBEROSKY, A. Psicogênese da Lingua Escrita. Porto Alegre: Artes Médicas, 1985.

GERALDI, J. W. Portos de Passagem. São Paulo: Martins Fontes, 1991.

KATO, M. A. No mundo da escrita: uma perspectiva psicolinguística. 7 ed. São Paulo: 2009.

MARCUSCHI, L. A. Produção textual, análise de gêneros e compreensão. São Paulo: Parábola, 2008.

ORLANDI, E. P. Discurso e leitura. São Paulo, SP: Cortez, 2000. 
ROCHA, G. et al. Avaliação da alfabetização: como usá-la em sua função diagnóstica? In: . Guia da Alfabetização. Belo Horizonte: Segmento, 2010, p. 78-90.

SCLIAR-CABRAL, L. Princípios do Sistema Alfabético do Português do Brasil. São Paulo: Contexto, 2003a.

SCLIAR-CABRAL, L. Guia Prático de Alfabetização. São Paulo: Contexto, 2003b.

SOARES, M. A reinvenção da alfabetização: Presença Pedagógica. Belo Horizonte, Dimensão, 2003, p.1-21.

. Letramento: como definir, como avaliar, como medir. In: SOARES, M. Letramento: um tema em três gêneros. Belo Horizonte: Autêntica, 1999.

\section{The appropriation of reading and writing skills in literacy: an exploratory study of data from an external evaluation}

\section{Abstract}

This paper analyzes the development of writing skills in the early years of Elementary School, referring to large scale literacy assessment, using a longitudinal program called Evaluation of Basic Education of the State of Espírito Santo Program (Programa de Avaliação da Educação Básica do Estado do Espirito Santo - Paebes Alfa). The written data is also analyzed in its dialogue with the reading data. Thus, in addition to discussing types of items used in this writing assessment, we make an analysis that provides a contribution to the understanding of differences between reading and writing skills which are also often perceived as "faces of the same coin", that is, such as learning styles that occur simultaneously and indistinctly. As the analysis here indicates, the consolidation of literacy, decoding skills tend to occur before coding skills. Keywords: External evaluation. Writing. Elementary school. Paebes Alfa. 


\section{La apropiación de la lectura y de la escritura en la alfabetización: estudio exploratorio de los datos de una evaluación externa}

\section{Resumen}

Este trabajo analiza el desarrollo de la escritura en el primer ciclo de la escuela primaria, apoyándose en la evaluación a gran escala de la alfabetización, de naturaleza longitudinal, llamada Programa de Evaluación de la Educación Básica del Estado de Espírito Santo - Paebes Alfa - Brasil. Los datos de la escritura se observan y estudian dentro de un diálogo con la lectura. Por lo tanto, además de discutir los tipos de items de escritura utilizados en la evaluación externa al ámbito escolar, se hace un análisis que ayuda a comprender las diferencias entre las habilidades de lectura y de la escritura, a menudo percibidas como "caras de la misma moneda", es decir, como un aprendizaje que se produce de forma simultánea e indistintamente. Como lo señala el análisis realizado, durante la consolidación de la alfabetización, las habilidades de decodificación tienden a ocurrir antes que las habilidades de codificación.

Palabras clave: Evaluación externa. Escritura. Enseñanza primaria (primer ciclo). Paebes Alfa 